\title{
ESTUDO SOBRE A RELAÇÃO ENTRE O LAZER E O TRABALHO DO GUIA DE TURISMO REGIONAL DO ESTADO DO RIO GRANDE DO NORTE ${ }^{1}$
}

\author{
Recebido em: $18 / 11 / 2017$ \\ Aceito em: 05/05/2018 \\ Pâmella dos Santos Fernandes ${ }^{2}$ \\ Instituto Federal do Rio Grande do Norte \\ Parnamirim - RN - Brasil \\ Juliana Vieira de Almeida ${ }^{3}$ \\ Universidade Federal do Rio Grande do Norte \\ Natal - RN - Brasil
}

RESUMO: Este trabalho é resultado de uma pesquisa sobre a temática do lazer no âmbito da profissão do Guia de Turismo Regional do estado do Rio Grande do Norte, cujo objetivo foi identificar se esse profissional vivencia o lazer durante o exercício de sua profissão. Como abordagem metodológica optou-se pela pesquisa exploratóriodescritiva e entrevistas semiestruturadas. $\mathrm{O}$ resultado da pesquisa permitiu inferir que há a percepção e a vivência do lazer na execução de sua atividade do Guia de Turismo, assim como, observou-se que as vivências de lazer desse profissional são de uma natureza diferente daquelas vivenciadas pelo seu cliente (turista), na medida em que este deve estar sempre atendo e apto a resolver possíveis imprevistos e problemas que possam surgir, assim como estar sempre à disposição do cliente para atender suas necessidades.

PALAVRAS CHAVE: Atividades de Lazer. Trabalho. Guia de Turismo.

\section{STUDY ON THE RELATIONSHIP BETWEEN THE LEISURE AND THE WORK OF THE REGIONAL TOURISM GUIDE OF THE STATE OF RIO GRANDE DO NORTE}

ABSTRACT: This work is the result of a research on the theme of leisure within the profession of the Guide of Regional Tourism of the state of Rio Grande do Norte, whose objective was to identify if this professional experience leisure during the exercise of his profession. As a methodological approach we opted for exploratory-descriptive research and semi-structured interviews. The result of the

\footnotetext{
1 Artigo premiado no $29^{\circ}$ Encontro Nacional de Recreação e Lazer (ENAREL), realizado em Caruaru/PE em 2017.

${ }^{2}$ Graduada no Curso Superior em Tecnologia em Gestão Desportiva e de Lazer - IFRN - Instituto Federal de Educação, Ciência e Tecnologia do Rio Grande do Norte.

3 Doutora em Educação pela Universidade Federal do Rio Grande do Norte e Pós- Doutora em Ciências Sociais pela Universidade de Minho em Portugal.
} 
research allowed to infer that there is the perception and the experience of the leisure in the execution of its activity of the Guide of Tourism, as well as, it was observed that the leisure experiences of this professional are of a nature different from those experienced by its client (tourist), since it must always be able to solve problems and problems that may arise, as well as being always available to the customer to meet their needs.

KEYWORDS: Leisure Activities. Work. Tourism Guide.

\section{Introdução}

Lazer e trabalho são fenômenos que, por muito tempo, foram vistos como opostos. Para Gomes (2008a), atualmente acredita-se ser difícil visualizar um afastamento entre ambos, sobretudo, que existam fronteiras absolutas entre o lazer e o trabalho, e, ainda mais entre o lazer e as demais obrigações religiosas, sociais, familiares, políticas e profissionais.

A busca pela satisfação, motivação e bem-estar tem sido um movimento constante ao longo da história humana. Nos dias de hoje, comumente percebe-se que, quando em período de férias, as pessoas logo recorrem à atividade turística como alternativa para escapar do estresse causado pela rotina diária e pelos cenários cada vez mais competitivos e instáveis que caracterizam o Século XXI.

Para Panosso Netto (2013, p.15), "o turismo é uma das formas mais características do lazer atual, pois, surge como fuga do estresse da rotina de trabalho e do cotidiano". Ou seja, as pessoas buscam na atividade turística a satisfação pessoal, descanso, descontração e momentos de lazer. O turismo é um fenômeno diferenciado e para acontecer, assim como o lazer, necessita que o indivíduo tenha uma motivação. Existem diferentes tipos de turismo, justamente por haver motivações de diferentes naturezas, entre os quais destacamos o denominado Turismo de Lazer, que segundo Campos e Gonçalves (2005), é o turismo com maior demanda e 
aquele no qual destaca-se como principal motivação: o desejo de aliviar as tensões causadas pela rotina de trabalho; recuperação da capacidade fisica e mental e o relaxamento e a recarga de energias. Nesse segmento de turismo as opções são variadas, a saber: visitar centros urbanos; praias; ambientes rurais; realização de práticas esportivas; entre outros. É, sobretudo, nesse segmento da atividade turística que se encontra a figura do guia de turismo, sendo este o responsável por interpretar e traduzir o patrimônio material e imaterial para os visitantes, bem como proporcionar descontração e bem-estar ao longo do serviço prestado.

Destarte, considera-se que o guia de turismo representa a essência da atividade turística em si e não apenas um orientador, acompanhante ou vendedor, ainda que seja dele exigido o atendimento aos interesses da agência de viagem contratante, para a qual, geralmente, atua como prestador de serviços eventual (free-lancer), sendo ele o responsável por assegurar a satisfação e o atendimento ao que foi acordado entre empresa e cliente (LEME, 2010). A temática objeto deste estudo diz respeito, portanto, à análise do contexto profissional do guia de turismo, a fim de analisar se este percebe ou vivencia o lazer durante o exercício do seu trabalho.

Este estudo destina-se a refletir sobre o cotidiano dessa profissão, por considerá-la essencial para a atividade turística, responsável por fazer a interação do visitante com a localidade e principalmente com a comunidade que ali residente. Sobre a profissão, destaca-se o pensamento de Canani (1999, p. 95): “é preciso que a sua imagem, como um mero indicador, seja modificada pela sua real função: apoiar, esclarecer e vivenciar, junto ao turista, o mesmo desejo de satisfação e prazer que este tem." 


\section{O Trabalho, o Lazer e o Turismo}

Trabalho é uma palavra derivada do vocábulo latino tripaliare, do substantivo tripalium, um instrumento de tortura formado por três paus utilizado, na Idade Antiga, para subjugar os animais e forçar os escravos a aumentar a produção. A representação do trabalho, portanto, foi (por muito tempo) atrelada a uma imagem negativa ligada à ideia de sacrifício (RIBEIRO; LÉDA, 2004). Posteriormente, na Idade Média, a representação do trabalho recebeu forte influência da igreja católica, sendo vista como atividade atribuída a servos, assim como, sob a forma de punição pelos pecados. A Revolução Industrial, iniciada no Século XVIII, vai atribuir ao trabalho uma visão diferenciada e contribuir para que seja percebido como atividade essencial ao desenvolvimento do capitalismo, ao passo em que o lazer começa a ser considerado uma recompensa pelo esforço empreendido. Para Gomes (2008a), o lazer e o trabalho foram apresentados como elementos de polos opostos, sendo o primeiro sinônimo de liberdade (e livre de qualquer obrigação) e o segundo como sinônimo de necessidade.

O conceito de lazer, elaborado pelo autor francês Jofre Dumazedier, foi utlizado como referência no Brasil e em diversos países. O autor conceitua lazer como:

[...] um conjunto de ocupações às quais o indivíduo pode entrega-se de livre vontade, seja para repousar, seja para divertir-se, recrear-se e entreter-se, ou, ainda para desenvolver sua informação ou formação desinteressada, sua participação social voluntária ou sua livre capacidadade criadora após livrar-se ou desembaraçar-se das obrigações profissionais, familiares e sociais (DUMAZEDIER, 1976, p.34).

Segundo Gomes (2008b), este conceito enquadrou-se bem à época em que fora formulado, posto que teve como conjuntura as sociedades industriais do Século XX. $\mathrm{Na}$ atualidade, depara-se com uma sociedade diversa daquela, agora mais voltada para a prestação de serviços, o que demonstra a necessidade de um novo olhar para o conceito de lazer. Dumazedier (1976) definiu o lazer em oposição ao conjunto de 
obrigações e necessidades da vida cotidiana, especialmente do trabalho profissional, interpretação hoje com muitos questionamentos. Já para Gomes (2008a, p. 2) "trabalho e lazer, apesar de possuírem caracteristicas distintas, integram a mesma dinâmica social e estabelecem relações dialéticas." Ao considerar ambos os autores, depreende-se que trabalho e lazer não constituem lados opostos, posto que na vida cotidiana atual o que mais se observa é a co-existência desses (lazer e o trabalho) e das demais obrigações sociais.

Para Marcellino (1996), não é a atividade em si que caracteriza o lazer. O lazer é subjetivo, o que pode ser lazer para uma pessoa, pode não ser para a outra. A construção social do lazer é encontrado de diversas formas nas culturas, nas sociedades e nos diferentes tempos históricos. O lazer é visto e representado de várias formas, o mesmo pode ser diferente e se modificar de acordo com a classe social, o gênero, dos aspectos culturais e regionais e entre outros (GOMES; PINTO, 2009).

[...] o lazer é um fenômeno dialógico e, mesmo que o sujeito esteja em busca de satisfação, maior flexibilidade e liberdade de escolha, nem sempre estará isento de obrigações sociais, familiares, profissionais, etc (GOMES ; PINTO, 2009, p. 99-100).

O lazer, assim como a saúde e a educação, é garantido como um direito social (mais especificamente no Brasil), a partir da Constituição da República Federativa de 1988. Tal constatação, enfatiza a importância do lazer na vida das pessoas assim como a saúde e a educação. Dentro desse contexto insere-se o entendimento do turismo, enquanto uma complexa atividade na qual, se envolve o deslocamento de pessoas com a pretensão de desenvolver atividades de lazer que satisfaçam seus desejos (SANTANA, 2009). Para Gomes e Pinto (2009, p. 92), “[...] De modo diferente das épocas anteriores, na atualidade o campo do lazer passou a 
exigir mão de obra diversificada e qualificada para atender aos novos empreendimentos e demandas".

O Brasil é um país constituído de diversas identidades culturais, o que explicita a pluralidade do seu povo diversos temas e cenários. Segundo a autora Cristianne Luce Gomes (2008a, p. 62), pode-se afirmar que “[...] o lazer é uma dimensão da cultura construída conforme a peculiaridades do contexto a qual é desenvolvido". Sendo o lazer uma dimensão da cultura, o mesmo também acompanha as transformações ao longo do tempo. Dentro desse contexo, Christianne Luce Gomes (2004, p.126) conceitua lazer como:

[...] uma dimensão da cultura constituída por meio da vivência lúdica de manifestações culturais em um tempo/espaço conquistado pelo sujeito ou grupo social, estabelecendo relações dialéticas com as necessidades, os deveres e as obrigações.

De acordo com Brasileiro (2013), a contemporaneidade e suas mudanças (ocorridas ao longo dos anos) dá ao lazer um formato plural, pois diferentes atividades que antes relizavam-se separadamente, atualmente, acabam que se misturando e interagindo entre si, com diferentes afinidades e valores, produzindo estruturas próprias. Essa mesma sociedade é facilmente influenciada pelas mídias sociais, pelos meios de comunicação e pelas novas tecnologias. Vive-se num período de grande fluxo de conhecimento, informação e imagens construídas aparentemente de maneira interdependente, como afirma Alves (2003). A televisão e a internet têm sido apontadas como atividades que configuram o lazer no Brasil, sendo a televisão a mais presente no cotidiano dos brasileiros como opção de lazer (GOMES; PINTO, 2009).

No que tange à relação entre lazer e trabalho, Stênico e Paes (2016) relatam que por muito tempo ambos eram considerados elementos de campos opostos, que, 
posteriormente, culminou com o entendimento de tempo livre como um complemento do trabalho e, na atualidade, na concodância de que lazer e trabalho podem ser vistos com uma relação intensa e, portanto, difícil de separar. Um exemplo disso pode ser visto em algumas empresas que adotam espaços para descanso e lazer em suas instalações, na expectativa de que isso possa otimizar as relações interpessoais e aumentar a produtividade.

Significa dizer que nos tempos atuais fica evidente a dificuldade em separar o lazer das demais obrigações, para De Masi (2000), o indivíduo acaba levando o trabalho para casa devido a cabeça não parar de pensar, principalmente em achar soluções para os problemas de trabalho. Atualmente, até mesmo a tecnologia acaba sendo invasora do considerado tempo de lazer e acaba por conduzir situações ou problemas de trabalho para o seu tempo livre, seja na folga trabalhista ou até mesmo nas férias.

O turismo, por sua vez, é uma atividade complexa que se expande e se manifesta em acordo com os contextos históricos de cada sociedade. Esses contextos recebem a interferência de aspectos culturais, políticos, econômicos, entre outros. O turismo contemporâneo, nesse sentido, ainda que seja considerado como uma atividade recente para a utilização do tempo livre, emerge como principal escolha daqueles que buscam a prática do lazer.

A atividade turística se fortaleceu significativamente com o capitalismo industrial, período este marcado pelas conquistas sociais dos trabalhadores, como: conquista das férias, $13^{\circ}$ salário, redução da jornada de trabalho, entre outros. Outro fator que ajudou muito no fortalecimento do turismo foi o desenvolvimento tecnológico, responsável por facilitar, significativamente, o deslocamento e a 
comunicação das pessoas durante suas viagens. Todo esse cenário propiciou que (com o passar do tempo) o lazer, sob a forma de turismo, passasse a ser considerado como um produto de consumo desejável (embora nem sempre acessível à maioria da população mundial) e, por conseguinte, um símbolo de status. Segundo Mário Beni (2003), a atividade turística é o resultado da soma de bens culturais, sociais e econômicos, juntamente com os recursos naturais, possuindo assim um campo de estudo complexo, abrangente e pluricausal. Já para com Casey (2011), nas últimas décadas o turismo tem se desenvolvido de maneira significativa, transformando-se em um potente gerador de renda para muitas localidades. Desta forma, o autor ressalta a importância de estes lugares remeterem aos seus visitantes tranquilidade e um bom lugar para viver e relaxar.

De acordo com Panosso Netto e Trigo (2009), o setor de turismo sofreu profundas transformações ao longo das últimas décadas, principalmente, para atender ao mercado que ficou mais competitivo e passou a exigir mais qualidade profissional. O turismo é, portanto, um fenômeno diferenciado e que para acontecer, assim como o lazer, necessita que o indivíduo tenha, entre outros elementos, uma motivação. Existem diferentes segmentos de mercado turístico ligados à motivações específicas, entre eles, destaca-se o chamado Turismo de Lazer, atividade que, de acordo com Campos e Gonçalves (2005), é o turismo mais procurado pela demanda turística e no qual pode-se destacar como principal motivação o desejo de aliviar as tensões causadas pela rotina de trabalho, recuperação da capacidade física e mental, relaxamento e recarga de energias. No turismo de lazer as opções são variadas e vão, por exemplo, desde conhecer centros urbanos, praias e interior até a realização de práticas esportivas. 
Destarte, pode-se inferir que o turismo, no mundo contemporâneo, apresenta-se como uma das atividades mais expressivas do lazer. Para os autores que defendem o turismo como um dos interesses do lazer (MARCELLINO, 1996; CAMARGO, 2003) tanto o lazer como o turismo apresentam pontos convergentes, a saber: o caráter liberatório; a busca pelo prazer e a liberdade de escolha, conforme assevera, também, Dumazedier (1980). Já para Segundo Panosso Netto (2013), o turismo é uma atividade em que o indivíduo busca a liberdade do estresse contínuo causado pela rotina de trabalho, busca conhecer novos ares, novas pessoas, muitas vezes recorre à atividade para buscar uma resposta ou até mesmo um sentido para a vida.

De acordo com Taschner (2000), as atividades de lazer são consumidas através do intermédio do mercado, sendo a cultura a designadora das preferências dos consumidores. Entendendo a cultura como algo que está em constante transformação, como um fenômeno plástico, entende-se que ao longo dos anos as preferências sofrem mudanças (SILVA, 2013). A cultura é algo, que segundo Bauman (2013), tem a função de criar novas necessidades e não de manter ou satisfazer as necessidades que já existem, tendo a preocupação de não causar satisfação, incentivando sempre o consumismo. Ainda de acordo com o autor, a cultura tem o papel de sempre estar se reinventando, ou seja, está em uma constante mudança. 


\section{Profissão: Guia de Turismo}

De acordo com a Embratur, decreto $n^{\circ} 946$ de $1^{\circ}$ de outubro de 1993, é considerado guia de turismo:

[...] o profissional que, devidamente cadastrado na EmbraturInstituto Brasileiro de Turismo, [...] exerça as atividades de acompanhamento, orientação e transmissão de informações a pessoas e grupos, em visitas, excursões urbanas, municipais, estaduais, intermunicipais, internacionais ou especializadas.

O guia de turismo é um dos principais protagonistas no complexo cenário da atividade turística (CANANI, 1999). Esse profissional deve acompanhar e orientar seus clientes (turistas) na visitação de locais de interesse turístico, geralmente componentes da chamada "oferta turística" de uma determinada destinação. Tem, ainda, que realizar o seu trabalho de forma a obter do cliente um sentimento de satisfação e, de si próprio, um sentimento de realização, angariando de clientes, da empresa: confiança e fidelidade. Apesar de ser uma atividade considerada antiga em nosso país, a profissão de Guia de Turismo só foi considerada uma profissão no ano de 1986 e regulamentada no ano de 1993, pela Lei $\mathrm{n}^{\circ} 8.623$, de 28 de janeiro de 1993.

Com a regulamentação da profissão, o profissional passou a ter a obrigatoriedade de passar por um curso de nível técnico em instituições de ensino cadastradas, regulamentadas e autorizadas pela EMBRATUR - Empresa Brasileira do Turismo ${ }^{4}$. A formação profissional realizada em instituições de ensino de credibilidade e a partir de um currículo mínimo de horas e disciplinas obrigatórias, são indicativos da importância da profissionalização da atividade e da necessária

\footnotetext{
4 Atualmente, cabe ao Ministério do Turismo (MTur) o acompanhamento e fiscalização dessa formação.
} 
presença deste profissional na atividade turística, assim como da relevância da qualidade e segurança do serviço prestado por ele (LEITTE ;SOARES, 2016).

Atualmente, o Guia de Turismo ainda se depara no mercado de trabalho com pessoas que atuam no exercício da profissão de maneira ilegal, desenvolvendo o papel profissional sem o devido cadastro nos órgão oficiais da área. Segundo Leite e Soares (2016), isso se dá por falhas na fiscalização e, consequentemente, propiciando a atuação dos indivíduos sem formação específica e, por conseguinte, não credenciados. De acordo com o Decreto Nacional nº 946 (1993), em seu artigo $3^{\circ}$, o guia de turismo pode ser categorizado, como:

I - Guia Regional - quando suas atividades compreenderem a recepção, o traslado, o acompanhamento, a prestação de informações e assistência a turistas, em itinerários ou roteiros locais ou intermunicipais de uma determinada unidade da federação, para visita a seus atrativos turísticos;

II - Guia de Excursão Nacional - quando suas atividades compreenderem o acompanhamento e a assistência a grupos de turistas, durante todo o percurso da excursão de âmbito nacional ou realizada nos países da América do Sul, adotando, em nome da agência e turismo responsável pelo roteiro, todas as atribuições de natureza técnica e administrativa necessárias à fiel execução do programa;

III - Guia de Excursão Internacional - quando realizarem as atividades referidas no inciso II, deste artigo, para os demais países do mundo; e

IV - Guia Especializado em Atrativo Turístico - quando suas atividades compreenderem a prestação de informações técnicoespecializadas sobre determinado tipo de atrativo natural ou cultural de interesse turístico, na unidade da federação para qual o profissional se submeteu à formação profissional específica (MINISTÉRIO DO TURISMO, 2014).

O guia de turismo não é apenas um profissional que é pago para viajar ao redor do mundo (o que à primeira vista pode parecer um sonho); ele é um profissional que, dentre outras responsabilidades e atribuições, representa uma empresa (agência ou operadora), perante seus clientes (MAMEDE, 2003). Ele é, muitas vezes, a parte visível de empresas, instituições e destinos turísticos, 
portanto, parte responsável pela boa imagem da destinação aos olhos dos seus visitantes.

Sobre o exercício da profissão, destaca-se que:

[...]Geralmente são esses profissionais que fazem o receptivo dos turistas que acabaram de desembarcar em um determinado destino e que, além de suas bagagens, trazem consigo expectativas, sonhos, anseios ou necessidades específicas. Logo, espera-se que seja alguém bem preparado e responsável para exercer tal profissão - uma das mais importantes do turismo, devido ao seu alto grau de complexidade. Enfim, por todas suas funções e atribuições esse profissional acaba se tornando um vendedor em potencial (NASCIMENTO; SILVA; GRECHI, 2014, p. 27).

Vale ressaltar, ainda que esse profissional também seja atingido pela precarização de benefícios previdenciários e proteção da legislação trabalhista, pelo fato de trabalhar de forma autônoma (REZENDE; COLETTO; ALVES, 2016). Atualmente, percebe-se que muitos profissionais optam pelo formato de Microempreendedor Individual (MEI), a fim de poder ter direito a benefícios previdenciários, atuar de forma legalizada e emitir (quando necessário) notas fiscais pelos serviços prestados, para pessoas jurídicas, por exemplo.

Sendo intangível a prestação de serviços turísticos, o profissional envolvido na atividade deve estar atento em proporcionar uma experiência única, digna de ser percebida como um serviço gratificante pelo seu cliente. De acordo com Neide Deluiz (1994 apud SENAC 2007, p. 38), existem algumas competências que são exigidas desse profissional que, além de possuir excelente formação técnica, deve desenvolver algumas competências humanas e comportamentais para ser considerado um profissional competente e de excelência, a saber: intelectuais/técnicas; organizacionais/ metódicas; comunicativas; sociais e comportamentais. 
A fim de desenvolver esse rol de comportamentos, habilidade e atitudes, Chimenti e Tavares (2007) e Neide Deluiz (1994 apud SENAC 2007), sugerem:

- Intelectuais/Técnicas: aprender a pensar, identificando, reconhecendo e definindo problemas; formulando alternativas; equacionando soluções; solucionando imprevistos e avaliando resultados; pensar estrategicamente, respondendo criativamente às novas situações, atuando preventivamente e introduzindo modificações em processos de trabalho e integrando atividades na qual domina os conceitos e tarefas; e ser um bom vendedor.

- Organizacionais/ Metódicas: ser muito organizado; saber gerenciar tempo e espaço; estabelecer métodos próprios para diferenciar-se dos demais; ser flexível.

- Comunicativas: considerada uma das principais competências (pois se trata de uma profissão que exige saber se comunicar com clareza e objetividade), deve ser capaz de transmitir emoção, confiança e segurança aos turistas; discutir e apresentar ideias; comunicar-se equipe de trabalho e com superiores hierárquicos; dialogar; negociar; argumentar; questionar etc.

- Sociais: saber trabalhar em equipe; ter empatia; ser paciente, simpático e o mais importante, saber lidar com as pessoas.

- Comportamentais: ser responsável; pontual; atencioso; ter liderança; iniciativa; motivação; criatividade; honestidade, capacidade de observação; curiosidade, agilidade, dinamicidade e estar aberto às mudanças.

Pode-se dizer, que a ferramenta de sucesso desse profissional não está apenas nos conhecimentos básicos exigidos, mas sim na forma como ele observa o mundo e o contexto específico de sua área de atuação e se adapta, sobretudo, 
pela constatação de que os seus ganhos financeiros estão diretamente ligados ao resultado de sua desenvoltura no trabalho e de suas vendas.

\section{Metodologia}

De acordo com Vergara (1998) e Gil (1991) a pesquisa pode ser classificada como: exploratória e descritiva. Exploratória, porque tem o objetivo de familiarizar-se com o problema obtendo uma visão do mesmo para que seja desenvolvida novas ideias. Descritiva, porque analisa, observa, registra e correlaciona os fatos, sem manipulá-los. Este estudo é baseado numa pesquisa qualitativa, que se preocupa com o aprofundamento da compreensão de um determinado grupo social. Esse tipo de pesquisa preocupa-se, portanto, com aspectos reais que não podem ser quantificados, centrando-se na compreensão e explicação da dinâmica das relações sociais na qual acaba que tendo um envolvimento emocional do pesquisador.

A presente pesquisa foi realizada no município de Natal no estado do Rio Grande do Norte e utilizou-se como instrumento de coleta de dados a entrevista semiestruturada realizada com onze guias de turismo regionais do estado do Rio Grande do Norte. A coleta de dados foi realizada no período de $1^{\circ}$ a 21 de março de 2017, seguindo a orientação de Fonseca (2002 apud SILVEIRA; CÓRDOVA, 2009), para quem a pesquisa de campo é aquela que se realiza a pesquisa de dados junto aos indivíduos, realizada por meio de observação e por entrevistas/questionários. Sendo uma pesquisa caracterizada pela investigação na qual procura o aprofundamento de uma realidade específica. De acordo com Vergara (2012), a entrevista é um dos métodos mais utilizados quando se trata de 
pesquisa de campo, pois a mesma trata da coleta de dados de forma que o pesquisador alcance as conclusões adequadas.

A pesquisa norteou-se pelo objetivo de identificar a percepção e a vivência do lazer por parte dos guias de turismo, durante o exercício de sua profissão, a fim de melhor compreender as questões relativas à natureza do seu trabalho e às problemáticas que possam vir a interferir na sua qualidade de vida.

\section{Resultados e Discussão}

Do total da amostra tem-se $27 \%$ dos entrevistados do sexo feminino e $73 \%$ do sexo masculino, na qual comprova-se a predominância do sexo masculino na profissão. Acredita-se que esse cenário tem relação com a natureza das atividades realizadas, a necessidade de viagens diárias e constantes, a predisposição para atividades diurnas e noturnas (no caso de roteiros by night), entre outros.

Ressalta-se que, em oposição ao cenário observado em campo, é maior o percentual de mulheres ingressantes nos cursos técnicos de formação em guia de turismo, como é o caso do IFRN, Campus Cidade Alta, instituição que oferta regularmente esse curso e que apresenta, segundo dados da sua Secretaria Acadêmica, desde a oferta da sua primeira turma (no ano de 2009) até o ano de 2017, a predominância de alunas ingressantes e concluintes.

A distribuição dos respondentes, quanto ao tempo que estão na profissão de Guia de Turismo, demonstrou que $27 \%$ atua há de 2 a 5 anos, 36,5\% de 6 a 10 anos e 36,5\% de 18 a 25 anos. A amostra demostrou, também, que 100\% dos entrevistados afirma estar consciente de que não estão em momentos de diversão, ou seja, que não podem aproveitar (da mesma forma que seus clientes) as alternativas de lazer do local, ainda 
que atuando em lugares que remetem e convidam à diversão, tais como piscinas, parques aquáticos, praias, passeios de buggys, quadriciclos, entre outros.

Os resultados coletados apontam, também, que os principais desafios da profissão (e que afetam na qualidade de vida desses sujeitos) envolvem a constatação de que: o trabalho é autônomo (sem vínculo empregatício); é vinculado à sazonalidade turística; é acirrada a competitividade entre os colegas de trabalho; a jornada de trabalho é extensa (geralmente superior a 12 horas por dia); para ter retorno financeiro é necessário trabalhar todos os dias, inclusive feriados e finais de semana, e por consequência disso, não há muito tempo para dedicar-se à família.

Os entrevistados apontam, ainda, que a parte positiva da profissão é o próprio ambiente de trabalho, pelo fato de ser bastante descontraído, tanto por parte dos outros colegas, como por parte dos turistas, esses pela natural predisposição positiva de quem está (geralmente) em período de férias. Corroboram esse sentimento a oportunidade de conhecer novas pessoas todos os dias, o que (na visão dos entrevistados) contribui para elevar sua visão de mundo e, também, aumentar o seu networking, pois acreditam que quanto maior for o seu conhecimento de pessoas, maior será a possibilidade de aumentarem seus ganhos; uma vez que a remuneração desses profissionais está atrelada (também) à sua capacidade de venda de produtos e serviços turísticos.

Uma última constatação versou sobre o lazer. Para os sujeitos entrevistados, o lazer fica muitas vezes restrito a momentos específicos dos passeios/ deslocamentos. Isso ocorre em virtude de sua sensação de responsabilidade e de proteção pelo grupo que estão conduzindo. Mas, apesar de todo esse contexto, na maioria das vezes, esse profissional usufrui da vivência de lazer no horário de seu trabalho, sobretudo, na 
contemplação do ambiente natural; na observação da fruição do lazer pelos clientes e, também, na prática da conversação com clientes ou colegas de trabalho.

\section{Conclusão}

O principal objetivo desta pesquisa foi de analisar se o Guia de Turismo Regional do estado do Rio Grande do Norte percebe ou vivencia o lazer durante o exercício de sua profissão, exatamente pela característica dessa profissão em aglutinar o trabalho, o lazer e o turismo. Os resultados apontaram que o profissional usufrui, até certo ponto, pois ele está ciente que, ainda que esteja em ambientes alusivos ao lazer e ao turismo, pesam em sua percepção os atributos e as características de sua ocupação que envolvem, em primeira instância: a responsabilidade com o seu cliente/turista. Além disso, a pesquisa colocou em relevo a constatação da necessidade da vocação profissional para o exercício da atividade de guiamento, com ênfase em aspectos humanos comportamentais, voltados à postura hospitaleira.

Este estudo permitiu constatar que a profissão do guia de turismo, apesar de seus desafios, é recompensadora para aqueles que a executam, na medida em que lhes oferece (além de outras coisas) um dia a dia diversificado, dinâmico e plural, no qual há pouco espaço para rotinas monótonas. Permitiu, ainda, contribuir com o esclarecimento sobre o papel e a importância desse profissional, enquanto tradutor, intérprete e revelador do patrimônio material e imaterial das destinações turísticas ao redor do mundo, assim como, como elemento essencial na garantia de um lazer dinâmico, seguro e de qualidade para todos os envolvidos. 


\section{REFERÊNCIAS}

ALVES, V.F.N. Uma leitura antropológica sobre a educação física e o lazer. In: WERNECK, C.L.G.; ISAYAMA, H.F. (Org.) Lazer, recreação e educação física. Belo Horizonte: Autentica, 2003. p. $83-114$.

BRASIL. MINISTÉRIO DO TURISMO. Portaria $\mathrm{n}^{0} 27$ : Estabelece requisitos e critérios para o exercício da atividade de Guia de Turismo e dá outras providências. Diário Oficial da União, Brasília, DF, Seção 1, p. 110-111, 31 jan. 2014. Disponível em: https://www.turismo.gov.br/legislacao/?p=117. Acesso em: 18 jul. 2017.

BRASILEIRO, M. D. S. O lazer e as transformações socioculturais contemporâneas. Revista Lusófona de Estudos Culturais, v. 1, n.2, p. 90 -108, 2013.

BAUMAN, Z. A cultura no mundo líquido moderno. Tradução de Carlos Alberto Medeiros. Rio de Janeiro: Zahar, 2013.

BENI, M. C. Análise Estrutural do Turismo. São Paulo: Senac, 2003.

CAMARGO, L. O. O que é lazer. 3. ed. São Paulo: Brasiliense, 2003.

CAMPOS, L.C.de A.M; GONÇALVES, M.H.B. Introdução a turismo e hotelaria. Rio de Janeiro: Senac Nacional, 2005.

CANANI, I. S. S. Guia de Turismo: o mérito da profissão. Revista Turismo em Análise, São Paulo, v.10, n.1, p.92-106, maio 1999.

CASEY, D. Gestão do lazer. In: ISAYAMA, H. F.; PINTO, L. M. S. M.; UVINHA, R. R.; STOPPA, E. A. (Org.) Gestão de políticas de esporte e lazer: experiências, inovação, potenciaidades e desafios. Belo Horizonte, Editora UFMG, 2011.

DELUIZ, N. Formação do trabalhador em contexto de mudança tecnológica. Boletim Técnico do Senac, Rio de Janeiro, v. 20, n. 1, p.14-25, jan./abr. 1994 apud DE MASI, D. O ócio criativo. Rio de Janeiro: Sextante, 2000.

DE MASI, D. O ócio criativo. Rio de Janeiro: Sextante, 2000.

CHIMENTI, S; TAVARES, A. M. Guia de turismo: o profissional e a profissão. São Paulo: Senac São Paulo, 2007.

DUMAZEDIER, J. Lazer e cultura popular. São Paulo: Perspectiva, 1976.

$\overline{\mathrm{SESC}}, 1980$.

Planejamento de lazer no Brasil: a teoria sociológica da decisão. São Paulo:

FONSECA, J. J. S. Metodologia da pesquisa científica. Fortaleza: UEC, 2002. Apostila apud SILVEIRA, D. T; CÓRDOVA F. P. A Pesquisa Científica. In: GERHARDT, T. E; SILVEIRA, D. T. (Org.) Métodos de pesquisa - coordenado 
pela Universidade Aberta do Brasil - UAB/UFRGS e pelo Curso de Graduação Tecnológica - Planejamento e Gestão para o Desenvolvimento Rural da SEAD/UFRGS. - Porto Alegre: Editora da UFRGS, 2009.

GIL, A. C. Como elaborar projetos de pesquisa. São Paulo: Atlas, 1991.

GOMES, C. L. Verbete Lazer - Concepções. In: GOMES, C. L. (Org.) Dicionário Crítico de lazer. Belo Horizonte: Autêntica Editora, 2004. p. 119 - 126.

Lazer, Trabalho e Educação: relações históricas, questões contemporâneas. 2.ed. ver. e ampl. Belo Horizonte: Editora UFMG, 2008a. 151p.

Lazer urbano, contemporaneidade e educação das sensibilidades. Revista Itinerarium. Rio de Janeiro, v.1, 2008b.

; PINTO, L. O lazer no Brasil: analisando práticas culturais cotidianas, acadêmicas e políticas. In: GOMES, C et al. (Org.). Lazer na América Latina/Tiempo libre, ócio y recreación en Latinoamérica. Belo Horizonte: Editora UFMG, 2009, p. $67-122$.

LEITE, F.C.L; SOARES, M.H.A. Guia de turismo: da origem da profissão a formação profissional. In: FÓRUM INTERNACIONAL DE TURISMO DO IGUASSU, 10. Anais... Foz do Iguaçu, 2016.

LEME, F.B.M. Guias de turismo de Salvador: olhares sobre a profissão e reflexões sobre o papel do guia como sujeito na cidade. CULTUR: Revista de Cultura e Turismo, v.4, n.2,p.19-37, 2010.

MAMEDE, G. Agências, viagens e excursões. Regras Juridicas, problemas e soluções. Barueri: Manole, 2003.

MARCELLINO, N.C. Estudos do lazer: uma introdução. Campinas: Autores Associados, 1996.

NASCIMENTO, A. O.; SILVA, L. F.; GRECHI, D. C. A atuação do guia de turismo em Mato Grosso do Sul (Brasil): Diagnóstico, aspectos conceituais e perspectivas para o segmento. Revista Hospitalidade. São Paulo, v. 11, n. 1, p. 23 - 44, jun. 2014.

PANOSSO NETTO, A; TRIGO, L. G. G. Cenários do turismo brasileiro. São Paulo: Aleph, 2009.

O que é turismo. São Paulo: Brasiliense, 2013.

REZENDE, Y.A.E; COLETTO, K.A; ALVES, K S. Relatos de trabalho e de vida dos Guias de Turismo das cidades de Ouro Preto, Tiradentes e São João Del Rei (MG). Perspectivas sociais, Pelotas, ano 4, n. 1, agosto, 2016.

RIBEIRO, C. V. S; LÉDA, D. B. O significado do trabalho em tempos de reestruturação produtiva. Estudos e pesquisas em psicologia, UERJ, Rio de Janeiro, v. 4, n. 2, 2004. 
SANTANA, A. Antropologia do turismo: analogias, encontros e relações. São Paulo: Aleph, 2009.

SENAC. DN. Qualidade em prestação de serviços. /Lourdes Hargreaves; Rose Zuanetti; Renato Lee et al. Rio de Janeiro: Senac Nacional, 2007.

SILVA, A et al. Cultura e ideologia. In: . Sociologia em movimento. São Paulo: Moderna, 2013.

SIlveIRA, D. T; CÓRDOVA F. P. A Pesquisa Científica. In: GERHARDT, T. E; SILVEIRA, D. T. (Org.) Métodos de pesquisa - coordenado pela Universidade Aberta do Brasil - UAB/UFRGS e pelo Curso de Graduação Tecnológica Planejamento e Gestão para o Desenvolvimento Rural da SEAD/UFRGS. - Porto Alegre: Editora da UFRGS, 2009.

STÊNICO, J. A. G.; PAES, M. S. P. Lazer: do tempo livre à dimensão cultural e as novas formas de alienação. Licere, Belo Horizonte, v.19, n.1, mar/2016.

TASCHNER, G. B. Lazer, cultura e consumo. RAE - Revista de Administração de Empresas. São Paulo, v. 40, n. 4, out/dez, 2000.

VERGARA, S. C. Projetos e relatórios de pesquisa em Administração. São Paulo: Atlas, 1998.

Métodos de coleta de dados no campo. 2. ed. São Paulo: Atlas, 2012.

\section{Endereço das Autoras:}

Pâmella dos Santos Fernandes

Av. Elisa Branco Pereira dos Santos, 9A- Parque das Nações

Parnamirim - RN - 59158-160

Endereço Eletrônico: pamellasantos2903@gmail.com

Juliana Vieira de Almeida

Av. Senador Salgado Filho, 1559 - IFRN Campus Ead

Natal - RN - 59015-000

Endereço Eletrônico: juliana.vieira@ifrn.edu.br 